\title{
Supravalvar aortic stenosis: a complication of aortic valve surgery
}

\author{
Diana R Holdright, G C Sutton
}

\begin{abstract}
After a patient had aortic valvotomy and aortotomy for the relief of valvar aortic stenosis supravalvar stenosis developed over the next six years.
\end{abstract}

\section{Case report}

A 3 month old boy had the morphological and developmental features of cretinism and was found to have congenital hypothyroidism. He rapidly improved when he was treated with thyroxine. He had a systolic murmur. When he was 5 years old his electrocardiogram showed changes consistent with left ventricular hypertrophy and his chest $x$ ray showed cardiac enlargement. He underwent cardiac catheterisation and angiography (figure) and was found to have valvar aortic stenosis with a peak systolic withdrawal gradient of 85-100 mm $\mathrm{Hg}$. Under cardiopulmonary bypass a $1 \mathrm{~cm}$ incision was made in the aorta. The aortic valve commissures were fibrosed and thickened and an aortic valvotomy was performed without complication.

After operation he remained well but with residual signs of left ventricular outflow

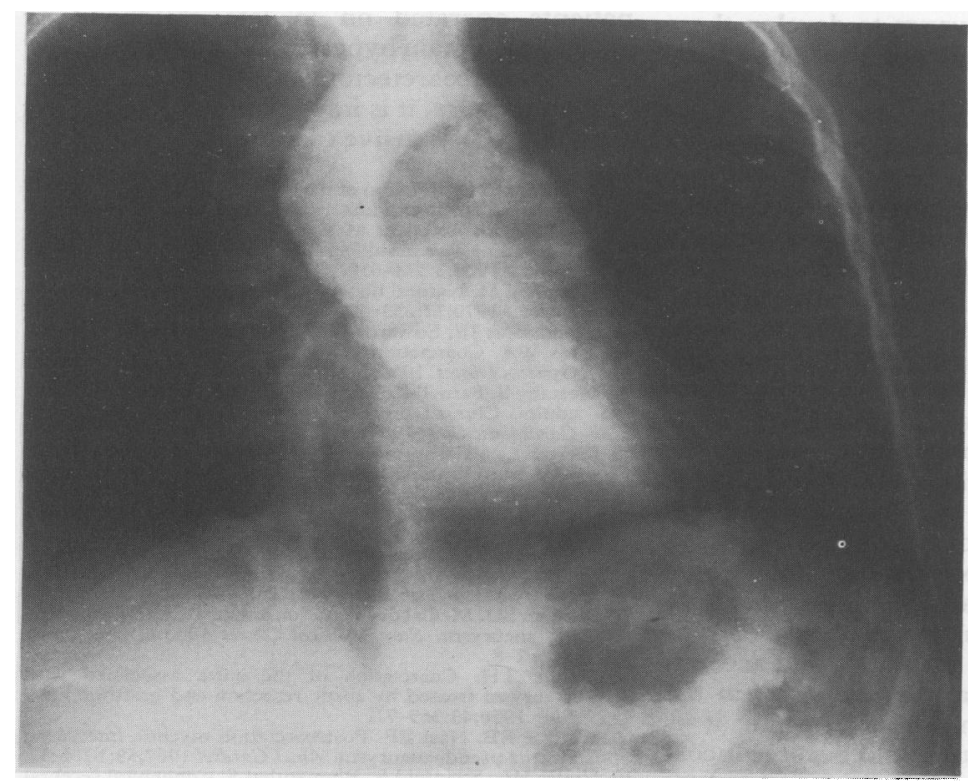

Angiogram before first operation. obstruction and evidence of left ventricular hypertrophy on his electrocardiogram. Because of the development of breathlessness at the age of 12 years repeat operation was considered. At this time he was in sinus rhythm with a blood pressure of $110 / 75 \mathrm{~mm}$ $\mathrm{Hg}$ and a sustained apical impulse. On auscultation there was an ejection sound in the second right intercostal space and an ejection systolic murmur (grade $4 / 6$ ) together with an early diastolic murmur at the left sternal edge. The cardiac diameter was at the upper limit of normal on plain chest $x$ ray and his electrocardiogram showed evidence of left ventricular hypertrophy. Cardiac catheterisation was not carried out again and he was referred directly for further operation.

At operation cardiopulmonary bypass was established. The pericardial cavity was obliterated by firm adhesions and the left ventricle was massively enlarged. There was a thrill over the ascending aorta but no poststenotic dilatation. The pulmonary artery and right ventricle were normal. The aorta was opened with a long oblique incision and the aortic valve examined. This was bicuspid with fusion of the right coronary and non-coronary cusps. Unexpectedly there was a supravalvar stenosis with a shelf above the left coronary cusp approximating the two commissures of that cusp to each other and overhanging the left coronary orifice. The internal diameter of the stenosis measured $1 \mathrm{~cm}$. The aortic incision was extended beyond the supravalvar stenosis and the fibrous shelf was excised. The aortic valve was replaced with a fresh homograft and a dacron gusset was inserted into the aortic root.

He made a good postoperative recovery with gradual regression of the electrocardiographic abnormalities. He still had a soft ejection systolic and an early diastolic murmur at the left sternal edge. Echocardiography 4 years later showed that the left ventricle was normal without hypertrophy or dilatation, and with good systolic function. The aortic cusps seemed to be normal. An indirect carotid pulse tracing showed a normal left ventricular ejection time. Cardiac catheterisation 5 years after operation showed a normally contracting left ventricle and mild to moderate aortic regurgitation on the aortogram. Fifteen years later his left ventricular ejection time was still normal and Doppler echocardiographic studies 18 years after operation showed a maximum gradient of $18 \mathrm{~mm} \mathrm{Hg}$ across the 
aortic valve, trivial aortic regurgitation, and no evidence of supravalvar stenosis.

\section{Discussion}

Supravalvar aortic stenosis was first described by Mencarelli in $1930 .^{1}$ In the 1950 s the first preoperative diagnosis was described and the first surgical repair documented. ${ }^{2}$ The association of supravalvar aortic stenosis with an elfin-like facies and infantile hypercalcaemia (Williams's syndrome) is well known but there are also descriptions of familial and sporadic cases of supravalvar stenosis without the other characteristics associated with Williams's syndrome. ${ }^{3}$ Our patient had none of the features suggestive of Williams's syndrome and his serum calcium concentration was normal.

Our patient was congenitally hypothyroid but an association between hypothyroidism and supravalvar aortic stenosis has not been described. Hutchins et al described a case of parafollicular cell ( $C$ cell) hyperplasia in a patient with supravalvar stenosis and suggested that $\mathrm{C}$ cell hyperplasia occurs in response to persistent hypercalcaemia and that thyrocalcitonin function is augmented rather than impaired. ${ }^{4}$ Despite the location of $\mathrm{C}$ cells within the thyroid gland we have not found any reports describing an association between supravalvar aortic stenosis and thyroid dysfunction.

Whatever the possible associations leading to supravalvar aortic stenosis, we have no evidence that this patient had supravalvar aortic stenosis before the first operation on the aortic valve. Although supravalvar aortic stenosis is often found in association with aortic valve abnormalities, review of the original angiogram before the first operation (figure) did not suggest either supravalvar obstruction or aortic hypoplasia. Nor was there any suggestion at the time of the first operation that the patient had supravalvar aortic stenosis. Morrow et al in a review of 43 cases of supravalvar aortic stenosis found 13 with associated abnormalities of the aortic valve. $^{5}$ Somerville and Ross described an unusual type of aortic valve stenosis associated with supra-aortic stenosis ${ }^{6}$ : the valve was grossly thickened and lumpy and the supraaortic stenosis was associated with aortic hypoplasia. The appearance of the aortic valve in our patient did not accord with Somerville and Ross's description nor was the aorta hypoplastic. The description of the supravalvar aortic stenosis in our patient was best described as "hourglass" rather than "membranous" or "hypoplastic".

We consequently do not believe that our patient had congenital supravalvar aortic stenosis but that the lesion was the result of local trauma at the time of the first operation and developed over the next 6 years.

We thank Professor M Yacoub for allowing us to report this case on whom he operated and Dr M Raphael for his advice on the original angiogram.

1 Mencarelli L. Stenosi sopravalvolare aortica d anello. Arch Ital Anat Istol Path 1930;1:829-41.

2 McGoon DC, Mankin HT, Vlad P, et al. The surgical treatment of supravalvar aortic stenosis. $J$ Thorac Cardiovasc Surg 1961;41:125-33.

3 Pansegrau DG, Kioshos JM, Durnin RE, Kroetz FW. Supravalvar aortic stenosis in adults. $\mathrm{Am} J$ Cardiol 1973;31:635-41.

4 Hutchins GM, Mirvis SE, Mendelsohn G, Bulkley BH. Supravalvar aortic stenosis with parafollicular cell (C-cell) hyperplasia. Am J Med 1978;64:967-73.

5 Morrow AG, Waldhausen JA, Peters RL, Bloodwell RD, Braunwald E. Supravalvar aortic stenosis. Clinical, hemodynamic and pathologic observations. Circulation hemodynamic and

6 Somerville J, Ross D. Congenital aortic stenosis-an unusual form. Consideration of surgical management. $\mathrm{Br}$ Heart $J$ 1971;33:552-8. 